\title{
Fictionally Flipping Tetrominoes? Defining the Fictionality of a Videogame Player's Actions
}

\author{
Nele Van de Mosselaer ${ }^{*}$
}

In this paper, I use the case of player actions in Tetris to explore possible problems in existing descriptions of videogame actions as fictional actions. Both in the philosophy of computer games and videogame studies, authors often make use of Kendall Walton's make-believe theory to describe videogame actions as fictional. According to the Waltonian description of fictional actions, however, the actions players perform when playing Tetris, such as flipping tetrominoes, would also be fictional. This is a counterintuitive idea, as players of Tetris seem to be really manipulating the graphical shapes in this game. I will thus discuss two other possible descriptions of fictional actions hinted at by Grant Tavinor (2009). Firstly, the (non-)fictional status of videogame actions might depend on the nature of the affordances to which they are reactions. Secondly, it might be the case that players must take on a role in the fictional world for their actions to be fictional. In the end, I will combine this second idea with a Waltonian description of fictional actions to form a new description of videogame actions as fictional actions that corresponds to and explains videogame players' experiences.

Keywords: video games, actions, affordances, fiction, player actions, fictional actions, avatar, imagination, make-believe, Walton.

We can save Little Sisters in Bioshock, help our team members in Mass Effect, kill orcs in Shadow of Mordor, and race spaceships in WipeOut. Players of computer games interact with fictional objects, save characters that are invented, and kill monsters that are clearly non-existent within worlds that are mere representations on a screen. But how should we understand these actions, which players say to perform while they are never really performed?

When describing situations as these, authors both in the philosophy of computer games and videogame studies often talk about fictional actions (Tavinor 2009; Matsunaga 2016; Robson and Meskin 2016; Velleman 2008). However, the concept of

A version of this paper was presented at the 2017 Philosophy of Computer Games Conference in Krakow, Poland. I would like to thank Dr. Al Baker for his comments, suggestions, and questions, which were both inspiring and shaping for the argument offered in this paper. 
fictional actions is not always unambiguously or explicitly described and it is thus not always clear how this concept has to be understood. In this paper, I will explore possible problems within existing descriptions of fictional actions by looking at examples of player actions that are not normally seen as being performed fictionally, such as moving blocks in Tetris, making use of exploits, and opening game menus. I will first describe the Waltonian way of defining fictional actions and discuss how this would force us to call player actions in Tetris fictional. I will then assess two possible new conditions for fictional actions hinted at by Grant Tavinor, who refuses to call player actions in Tetris fictional actions. The first possibility is that the (non-)fictional status of videogame actions depends on the nature of the affordances to which the players react (Tavinor 2009; Juul 2005). I will argue that this condition does not contribute to a better description of fictional actions. Another possibility is that the player must take on a role in the fictional world for his action to be called fictional (Tavinor 2009). This idea that actions can only be fictional if they are acted out through a proxy within a fictional world will prove helpful. In the end, I will use it to formulate a new description of fictional actions that allows us to usefully talk about them in a way that not only corresponds to the player's experience, but also accounts for it.

\section{Troublesome Fictional Actions}

Before we try and find ways to usefully describe fictional actions, we might ask ourselves: if fictional actions are so hard to describe, why do we want to talk about them at all? Although some theorists argue that videogame actions are best explained as the real actions of manipulating graphical objects via a controller (Sageng 2012; Juul 2005; Matsunaga 2016), I would argue we need fictional actions if we want to explain the gamer's experience. For example, when gamers shoot a zombie in a videogame, they do so because they want to kill the monster. It would be strange to say that they satisfy their desire by manipulating their controller and making a representation of a zombie die. Their desire can only be satisfied by the action of killing the zombie, which is obviously something they can only fictionally do. Moreover, when gamers emotionally react to one of their actions, like when they feel guilty for killing a certain character, it seems obvious that what they feel guilty about is their act of murder: a fictional action. When we cannot talk about what gamers fictionally do when playing games, their behavior becomes hard to describe and impossible to explain. But then, of course, we need a clear idea of what exactly fictional actions are.

\section{Fictional actions: a Waltonian Framework}

In 1990, Kendall Walton wrote Mimesis as Make-Believe, in which he formulated his highly influential make-believe theory, which describes and explains our experiences of and interactions with works of fiction. Although Walton never mentions videogames in his book (he started formulating his make-believe theory in the 1970s), two 
elements of his theory seem to make it easily applicable to this new fictional medium. First of all, Walton argues that when we appreciate fictional works, we don't just observe their fictional worlds from without, but live in them, "together with Anna Karenina and Emma Bovary and Robinson Crusoe and the others, sharing their joys and sorrows, rejoicing and commiserating with them, admiring and detesting them. True, these worlds are merely fictional, and we are well aware that they are. But from inside they seem actual - what fictionally is the case is, fictionally, really the case” (273). He argues that appreciators of fictional works "imagine, from the inside, doing things and undergoing experiences” (214). As Chris Bateman remarks, Walton's descriptions of the make-believe games played by readers of novels and viewers of movies gestures at something "players of digital games are intimately familiar with", since videogames allow us to enter their fictional world and experience them from the inside in an even more straightforward way (Bateman 2011, 167). Walton's theory thus seems especially appropriate to describe the videogame experience.

Secondly, Walton has an elaborate theory on pretence and children's games of makebelieve, in which he explains how it might be possible to perform fictional actions. His most famous example is that of two children playing a game in which they pretend tree stumps are bears (37). They use the tree stumps as props in a game of make-believe to imagine that there are bears. These props allow for physical interaction: when the children hit a tree stump, they can use their real action of hitting this fictional proxy of a bear as a prop to imagine that they are hitting a bear. By running away from the tree stumps, they make it fictionally true of themselves that they are running away from bears. In other words: they are fictionally running away from bears. Walton adds that all fictional works invite such make-believe games: a painting of a boat, for example, mandates a make-believe game in which the viewer sees a boat. This viewer then fictionally sees a boat (215). As Tavinor remarks, Walton's theory of make-believe is perfect to describe the videogame experience: "Given that participating with videogames is also primarily an act of engaging with a representational prop, such a theory of fiction is entirely apt to capturing the nature of the fictive practice involved in videogames" (2005, $30)$. Indeed, videogames seem to be model Waltonian props. The graphical representations on the screen can be used to imagine that the depicted events are really experienced by the player. Moreover, players can use the real actions they perform on controllers and the graphical representations they thereby create as a prop to imagine that they are actually performing actions within the fictional world.

Using this framework, we can not only describe when a player action is a fictional action, but also what exactly happens when the player fictionally does something: a player performs a fictional action $\varphi$ when they use their real action of manipulating a 
controller and thereby creating a graphical representation on the screen as a prop to imagine they really are doing $\varphi .{ }^{1}$ For example: a player performs the fictional action of shooting a zombie when they press a button on their controller to create a representation of a zombie being shot on the screen and uses this action as a prop to imagine they are shooting a zombie. Walton's theory also might explain why players feel like they are performing the fictional action, since they use their own action as a prop to imagine that they are doing the fictional action.

However, Walton's definition of fiction is quite wide-ranging and tends to define more player actions as fictional than the authors who use it want to. The most typical example of this is Tetris. Both the game itself and the actions performed by players of Tetris would be fictional in a Waltonian sense. As Robson and Meskin write:

\begin{abstract}
Walton treats 'representation' and 'fiction' as interchangeable-at least for certain purposes (Walton 1990: 3). This suggests that—in Walton's sense-most (perhaps all) videogames belong to the class of fictions. Even Tetris plausibly involves Waltonian representation. Of course if Walton is right about depiction then this is easy to establish, since the game plausibly involves pictures of tetrominoes and, hence, mandates imagining of one's looking at the display that it is an instance of looking at those tetrominoes spin and stack. But putting depiction aside, it seems to us that when playing Tetris one is supposed to imagine manipulating the tetrominoes. If this is right, then even Tetris counts as a walt-fiction and not merely in virtue of it involving pictures (2012b, 207).
\end{abstract}

According to a Waltonian description, when a player plays Tetris, they push buttons, create the representation of a turning tetromino, and imagine of their pushing of buttons that it is a flipping of tetrominoes. As many authors point out, however, it would be counterintuitive and unnecessary to call the actions a Tetris player performs fictional, as they only seem to be really manipulating the graphical shapes in this game (Sageng 2012, 229-230; Juul 2005, 167; Tavinor 2009, 24). Moreover, and probably even worse than the Tetris case, it is not exactly clear why opening a menu in a game wouldn't be a fictional action according to a Waltonian framework: the player uses their action of pressing a button as a prop to imagine that they are actually opening a menu. The fact that a Waltonian description of fictional actions seems to result in counting many more actions as fictional then authors in the philosophy of videogames and videogame studies want to, usually leads to a rejection of the Waltonian approach, often with explicit mention of Tetris (Tavinor 2009; Robson and Meskin 2016; Matsunaga 2016; Juul 2005).

This rejection has an important consequence though, as authors who want to reserve the idea of fictional actions to describe more 'obviously fictional' games, but think actions in Tetris need to be accounted for differently (namely, as non-fictional actions) seem to need a description of fictional actions which includes a condition that is not

John Richard Sageng describes player actions in representational games similarly, although he argues that the player's intention in this case is not to perform the fictional action, as I would argue, but to produce the representation of this action in the game (230). 
fulfilled by the act of flipping tetrominoes, but is fulfilled by saving Little Sisters, shooting zombies, flying spaceships and the like.

\section{Fictional Affordances}

One such condition can be found in Grant Tavinor's The Art of Videogames. Although Tavinor at first seems to agree with a largely Waltonian description of the player's experience $(2009,41)$, he never mentions Walton once when he finally describes player actions under the heading 'Acting in Game Worlds' (79-85). Here, Tavinor suggests a new condition that defines videogame actions as fictional actions:

The possibility of fictional action comes about when various elements of the fictional environment are given the potential to cue game events: or what we might call affordances for action. [...] A fictional affordance in the case of a videogame is thus an interactive aspect of a fictive representation that determines what a player can fictionally do (80).

Thus maybe, we might say a player's action is fictional when it is enabled by a fictional affordance, or an action possibility that is part of the fictional environment of the game. Players fictionally do something when they make use of the fictive means the game provides them with (Tavinor 2009, 109). ${ }^{2}$ In this description of fictional actions, Tavinor seems to depend on Juul's description of games as "half-real”, or consisting of rules and fiction. Affordances dependent on the rules of the game result in non-fictional actions, while affordances that depend on (fictional objects within) the fictional world of the game result in fictional actions. Opening a door in a videogame is then a fictional action because the possibility for this action is a part of the fictional world itself (the fact that, fictionally, there is a door, and it can be opened). Opening a menu in a game would not be fictional at all, because the possibility for this action is purely rule-based ("pressing start opens the menu"), and not embedded in the fictional world of the game. Tavinor himself indicates how this new description might fix the problem of being forced to call actions in Tetris fictional actions when he says that the interactive potential of the affordances in Tetris are completely exhausted by the formal structure of the game (108). In other words: in Tetris, the action possibilities of the player are completely determined by the rules of the game, without any fictive means being offered to the player. As such, the player is not fictionally, but really flipping the tetrominoes. Tavinor's description thus also aligns perfectly with the often-expressed intuition that actions in Tetris cannot be fictional because this game does not contain fiction (Sageng 2012, 229-230; Juul 2005, 167).

Tavinor's use of the concept of fictional affordances might offer a surprisingly simple definition of fictional actions that saves us from calling actions in Tetris fictional.

This description is also used by Tamer Thabet when he introduces the concept of fictional actions in Game Studies All Over the Place (2017, 42). 
When looking at more marginal cases, however, the new description of fictional actions as reactions to fictional affordances still raises some big problems. First of all, it is unclear what it means for affordances to be embedded in the fictional world of the game. On the one hand, Tavinor seems to shy away from using "fictional" in the Waltonian sense here, since he wants to exclude Tetris affordances from being interpreted as fictional. On the other hand, however, he does describe a fictional world in a videogame as a world with an imagined existence only $(2009,24)$. If that is the case, who is to say Tetris does not have a fictional world? The representations of tetrominoes slowly gliding down our screen in Tetris seemingly should make us imagine there are blocks falling down. This could mean there is a fictional, albeit very limited, world connected to Tetris, in which blocks fall down and stack. In "Definition of Videogames" Tavinor admits an imagining of this kind might be present in Tetris and concludes that "Tetris is indeed an ambiguous case, and a great deal more argument would be needed to establish whether it is or is not a case of interactive fiction" (2008). But if one is unsure whether Tetris has a fictional world, it becomes impossible to decide whether its affordances are fictionally embedded or not. The distinction between fictional and non-fictional affordances on which Tavinor wants to base the distinction between fictional and non-fictional actions then becomes quite difficult to grasp.

Secondly, Tavinor's description might do its job rather too well, as it may not only exclude Tetris-like cases, but also videogame actions that are intuitively fictional. An example might be found in Uncharted: Drake's Fortune. Players of this game discovered that the player-character Nathan Drake, if moved around in a quite unconventional way next to a wall, could walk through these walls. This exploit is called 'wall-clipping'. Note that it is not a fictional action possibility given by the fictional environment that Nathan can walk through walls. On the contrary, the fictional world of Uncharted is such that Drake is a human being and walls are impenetrable by both humans and bullets. It seems like Tavinor would agree that this kind of cheating is not a reaction to a fictional affordance, as he describes exploits as manipulations of games' encodings or as taking advantage of bugs in the game $(2009,107)$. Thus, when we walk through a wall in Uncharted, we are not responding to an affordance that arises from the fictional world of Uncharted. We are merely making use of a bug in Uncharted's coding. Fictionally, however, there does not seem to be a difference between a player shooting zombies in this game and a player walking through walls in this game. The only difference between both actions is that one, that of shooting zombies, is also part of the story world of Uncharted, while the fictional act of walking through walls is not. Tavinor would agree though, that being part of the story is not a necessary condition for being fictional (2009, 24), so that walking through walls can be fictional without belonging to Uncharted's story. We can thus fictionally walk through a wall, without responding to a fictional affordance. As such, the description of fictional actions as reactions to fictional affordances does not seem to do the job we want it to, and moreover exchanges the 
problematical distinction between fictional and non-fictional actions for the equally problematical distinction between fictional and non-fictional affordances.

It is also worth noting that Walton's make-believe theory provides us with concepts that could neatly explain the strange fictional behaviour of walking through walls. When walking through walls in Uncharted, we are using the game as a prop for a makebelieve game in which it was never intended to serve as a prop. Walton calls this kind of make-believe game an unofficial game: what is true in this make-believe game was never meant to be fictionally true in the world of the videogame, but it is fictionally true in our personal playing of it $(1990,406)$. Thus, although wall-clipping in the world of Uncharted is an unofficial action, it is still an action we can fictionally perform.

\section{Actions of a Fictional Proxy}

Although he does not really elaborate on it in detail, Tavinor suggests another condition by which we could identify fictional game actions, when he says: "In games without player-characters, the player directly manipulates the fictive qualities of the game without taking on a role in that world" (2009, 62). Tavinor describes the playercharacter as "the player's fictional proxy in the world of the game, allowing them the ability both to perceive and to act in the world of the game” (2009, 60). Tavinor suggests that players act fictionally when they act through an avatar, while they directly and really manipulate what is fictionally true in the game when they don't act through an avatar (as would be the case in Tetris).

Robson and Meskin retort that an avatar is not necessary at all for a player to perform fictional actions $(2016,168)$. They give the example of the racing game WipeOut. This game presents no avatar, but that doesn't mean players of this game 'directly manipulate what is fictionally true'. As Robson and Meskin argue, the player still performs fictional actions in the fictional world of WipeOut, as is made clear by the way players describe themselves, as "moving at breakneck speed" and "being hit by a missile", etc. (2016, 168). An avatar thus doesn't seem necessary for a gamer to be able to fictionally act. Robson and Meskin elucidate their claim by comparing it to a child's game Walton discusses: “According to Walton (1990, 209), when a child 'pushes a toy truck too small actually to ride in across the floor, it is probably fictional that he is driving it' just as, on our account, it is fictional of the player in WipeOut that she is driving the racing craft" (2016, 168).

Robson and Meskin certainly seem to be right, contra Tavinor, that you don't need an overtly represented avatar to make fictional actions possible in a videogame. The way they argue for this, though, is somewhat unfortunate, as their example of WipeOut still contains a very clear fictional role with which the player is to identify. WipeOut is a racing game, so it seems obvious that there is a mandate for the player to imagine that they are the driver of the racing spaceship. A different example, in which not only the 
representation of an avatar is absent, but there is not even character or object in the fictional world with which the player can imaginatively identify, might show that Robson and Meskin are actually on the same track as Tavinor: what is necessary for fictional actions is not an explicitly represented avatar, but that the player identifies with someone/something in the fictional world who can perform actions in that world. ${ }^{3}$

Tavinor himself provides us with examples of games without such a fictional role which the player is mandated to imaginatively fill: Tetris, Age of Empires and Rise of Nations (2009, 72). Another famous example might be The Sims. In these games, players are granted agency not as explicitly represented characters in the fictional world (players have no avatar), not as implied characters (there is no being in the fictional world with which players are mandated to identify), but just as themselves (players receive an interface that lets them give real commands to represented objects/characters). As such, when a player says that they flip a tetromino, they must be really flipping a representation of a tetromino. They can make it fictionally true in the fictional world that a tetromino turns, but the action they perform is not itself part of that world and thus cannot be fictional. For a player to be able to fictionally act, and not just really manipulate the fictionally represented world from the outside, there must be someone or something in the fictional world who they can identify with.

However, as Walton says that if someone sees a painting of a boat, and imagines it to be a real boat, they are fictionally seeing a boat, the Waltonian might retort that if you flip a representation of a tetromino, and imagine it to be a real falling tetromino, then surely you must be fictionally flipping a falling tetromino. That is not necessarily true, however. Just like Robson and Meskin did, we can clarify this point by comparing such a player situation with a child's game of make-believe. Imagine a child who is playing with a doll, imagining it to be a toddler, but not imagining herself to be part of the fictional world she imagines. She might imagine, for example, that the toddler can walk on its own, by pushing the doll forward. The girl thus pushes the representation of the toddler, imagining it to be a real toddler, but she does not fictionally push the toddler: fictionally, the toddler is walking on its own. ${ }^{4}$ In a very similar way, the player of The Sims can make the representation of a sim go swimming, imagining the sim to be a person who goes to swim, without fictionally making him go swimming: fictionally, in his own world, the sim is not forced by anyone to go to the pool. Similarly, the player of Tetris

3 In this regard, Chris Bateman's distinction between the representation of the avatar and the function of the avatar is quite interesting. He uses the term "doll” for the way the avatar is represented in a game and the term "avatar" to refer to the role the player fulfils in the game's fictional world $(2011,106)$. This is relevant here, as it seems to be Bateman's "avatar" that is necessary for the performance of fictional actions, not his "doll”. Although Tavinor is not quite clear on this, his further discussion seems to suggest that he understands "avatar" as Bateman does (Tavinor 2009, 72).

$4 \quad$ Walton suggests this example, but doesn't elaborate on it after stating that without a mechanical doll, it would be hard for the girl to make it fictional that the toddler can walk on its own $(1990,226)$. 
can make it fictionally true that a tetromino turns, without fictionally flipping it. Again, when players do not imagine to be part of the fictional world, the performance of their actions cannot be either: their actions are real manipulations of the fictional world, but not fictional actions. We can thus formulate a new condition for fictional game actions:

A videogame player can only be said to perform a fictional action $\varphi$ when the player imaginatively projects into (the situation of) someone/something who does $\varphi$ in the fictional world of the game.

This not only fixes the Tetris problem, as shown above, but also the problem of the opening of a game menu being called fictional: as the player who opens the menu does not imaginatively project into someone (or something) in the fictional world who does the opening of the menu, it is rather a real manipulation of game elements. ${ }^{5}$

This new condition has a few important consequences. A first one is that this new description of fictional actions still allows us to interpret Tetris as representing a fictional world, albeit a very limited one, without having to say that Tetris actions are fictional. The reason that no fictional actions are performed in Tetris is not because this game has no fictional world, as many authors have argued (Tavinor 2009, 24; Juul 2005, 167; Sageng 2012, 229), but because, even if there is a fictional world, no action a player of Tetris performs is done while imaginatively projecting into a character in this fictional world.

A second consequence is that the very same action in a videogame can be fictional or non-fictional. Take two players of The Sims who both, in their own playing of the game, make one of their sims go for a swim. One of them plays the game from an external standpoint, not imagining herself to be part of the fictional world that is inhabited by the sims (which probably corresponds to what The Sims mandates its players to imagine). Her actions make it fictional that one of the characters goes swimming, but, as has been said, she does not fictionally make this so. The other player, however, pretends to be an evil god in his playing of the game. Indeed, the only reason why he makes the sim go for a swim is to subsequently take the ladder out of the pool, leaving the sim to hopelessly drown. This player not only makes it fictional that the sim goes swimming, but also fictionally makes the sim go swimming: it is the player himself who, in the guise of an evil, all-controlling god in the fictional world of the game, makes the sim go to the swimming pool.

The above is an example of how actions in a game without an overt avatar can be fictional or non-fictional depending on the approach and imaginings of the player. When there is no clear fictional role to play, players might make them up for themselves.

Possible exceptions are games in which the menu is actually opened by the character the player controls. A possible example is Grand Theft Auto IV, which presents the game menu on the player-character's mobile phone. 
Games that do have an overt player-character, however, clearly mandate the player to imaginatively identify with this character. Playing Uncharted without imaginatively identifying with Nathan Drake would not only be hard and quite weird (because, how would you play the game and what would you imagine instead?), but also a clearly unofficial make-believe game to play with this game. ${ }^{6}$ As such, the fictionality of player actions is not entirely determined by the way the player decides to play or imagine: there are still proper ways a game is intended to be played, which would often be very hard or even impossible to reject in a personal playing of the game, and which decide whether and which actions in this game would normally be fictional or non-fictional.

Lastly, this discussion on fictional actions in videogames might reveal a potential criticism to Walton's theory. Walton said that readers and viewers are always making things fictionally true about themselves when appreciating a work of fiction, be it a novel, painting, play, or movie (1990, 215). For example, the person looking at a painting of a boat not only sees a fictional boat, but thereby also fictionally sees a boat, according to Walton. Walton acknowledges that this would lead to some odd questions: if a person looking at an image of a Pterosaur from the Jurassic period fictionally sees this creature that was never seen by any human being, who is actually doing this fictional seeing? And does this person have to imagine seeing the unseen? In Mimesis of MakeBelieve, Walton dismisses these kinds of questions, simply filing them under the heading of "silly questions", of which it would be pointless and inappropriate to investigate them any further (1990, 174-183). In a later article, Walton does treat these kinds of questions more thoroughly, saying that the person looking at this image can unproblematically imagine seeing the Pterosaur while at the same time imagining the beast was never seen by anyone (2013, 20-22). Videogames, however, show that the questions Walton identifies here are more problematical and that the way he treats them is unsatisfactory. After all, videogames introduce a whole new way of becoming part of the fictional world. Games like Uncharted let us enter their fictional world in the guise of a fictional proxy, in this case Nathan Drake. When we see something in Uncharted's world, we truly fictionally see it, made possible by the fact that we identify with someone inside the fictional world. When we see something in Tetris, however, it would be strange to say we are fictionally seeing something, because fictionally, there is no one in the world of Tetris watching the tetrominoes fall. Since Walton's theory says of every fictional work that its appreciation causes de se imaginings, however, it cannot distin-

$6 \quad$ Another unofficial make-believe game would be to open the menu in Uncharted, and pretend that Nathan Drake is somehow performing this action, as the action of opening the menu is clearly not done by any character from within the fictional world of the game. 
guish between games like Uncharted and games like Tetris, or between fictionally doing something and making something fictionally happen. ${ }^{7}$

\section{Conclusion}

It is ultimately an element of Walton's make-believe theory that made his theory seem perfectly applicable to videogames, namely the idea that appreciators always enter the fictional world of the work they appreciate $(1990,273)$, that stands in the way of differentiating between games as Tetris and games as Uncharted. After all, we don't enter into the fictional worlds of all games equally. While we quite obviously enter and influence the world of Uncharted from the inside, we only manipulate the (arguably fictional) world of Tetris from the outside. A Tetris player makes it fictionally true that tetrominoes turn, but does not fictionally flip them. Only actions players do from within, through a proxy in the videogame's fictional world, are intuitively interpreted as fictional actions. This allows us to formulate a new condition to add to the Waltonian description of fictional actions and make it compatible with our intuitive grasp of fictional actions: a videogame player can only be said to perform a fictional action $\varphi$ when the player imaginatively projects into (the situation of) someone/something who does $\varphi$ in the fictional world of the game. Of course, this condition alone does not explain what happens when players fictionally act, or how their real actions are related to their fictional ones. This is solved by adding this condition to the Waltonian description of fictional actions, which has already proven its worth by allowing us to explain the imaginative games the gamers play using their own actions as props and how these games might differ from the official make-believe games a videogame was intended to serve in. The full new description then becomes: a videogame player performs a fictional action $\varphi$ when the player imaginatively projects into (the situation of) someone/something who does $\varphi$ in the fictional world of the game, by performing a real action, such as the manipulation of graphical shapes through a controller, which the player uses as a prop to imagine that they (in the guise of the fictional proxy) are doing action $\varphi$.

\section{Games}

2K Games (2007). Bioshock. PlayStation 3.

Rockstar Games (2008). Grand Theft Auto IV. PlayStation 3.

BioWare (2007). Mass Effect. Xbox 360.

Monolith Productions (2014). Middle Earth: Shadow of Mordor. PlayStation 4.

Pajitnov, Alexey and Gerasimov, Vadim (1985). Tetris. PC.

We could possibly solve this by saying that, contrary to what Walton said, only works of fiction that mandate their appreciators to imagine that they are part of their fictional world (novels and movies that address their audience, or videogames that invite players to take control of some being in its fictional world), can make things fictionally true about them. 
The Sims. 2000. Maxis, PC.

Naughty Dog (2007). Uncharted: Drake’s Fortune. PlayStation 3.

Psygnosis (1995). WipeOut. PlayStation.

\section{References}

Bateman, C. (2011). Imaginary Games. John Hunt Publishing.

Juul, J. (2005). Half-Real: Videogames between Real Rules and Fictional Worlds. MIT press.

Matsunaga, S. (2016). Did You Really Get a Mushroom? Player's Fictional Actions in Videogame Playing. Aesthetics, 20, 89-102.

Robson, J. and A. Meskin. (2012a). Videogames and the First Person. In Mimesis: Metaphysics, Cognition, Pragmatics, edited by G. Currie, P. Kotako, and M. Pokorny. College Publications.

- (2012b). Fiction and Fictional Worlds in Videogames. In The Philosophy of Computer Games, edited by J. R. Sageng, H. Fossheim, and T. Mandt Larsen. Springer Science \& Business Media.

—. (2016). Videogames as Self-Involving Interactive Fictions. Journal of Aesthetics and Art Criticism, 74(2), 165-177.

Sageng, J. R. (2012). In-Game Action. In The Philosophy of Computer Games, edited by J. R. Sageng, H. Fossheim, and T. Mandt Larsen. Springer Science \& Business Media.

Tavinor, G. (2005). Videogames and Interactive Fiction. Philosophy and Literature, 29(1), 24-40.

—. (2008). Definition of Videogames. Contemporary Aesthetics, 6. http://www.contempaesthetics.org/newvolume/pages/article.php?articleID=492. Accessed on 20/02/2018.

- (2009). The Art of Videogames. John Wiley \& Sons.

Thabet, T. (2017). Game Studies All Over the Place: Video Games and Gamer Identities. SciELO EDUEL.

Velleman, J. D. (2008). Bodies, selves. American Imago, 65(3), 405-426.

Walton, K. L. (1990). Mimesis as Make-Believe: On the Foundations of the Representational Arts. Harvard University Press.

- (2013). Fictionality and Imagination Reconsidered. In From Fictionalism to Realism, edited by C. Barbero, M. Ferraris, and A. Voltolini. Cambridge Scholars Publishing. 